\title{
Is Brazil the Land of Happiness? A Comparative Study Using a Sample with Economics Students from UFPE and Purdue $^{*}$
}

\author{
Tiago V. de V. Cavalcanti** \\ Juliana Ferraz Guimarães ${ }^{* * *}$
}

José Ricardo Nogueira***

\begin{abstract}
In this article we study the level of happiness using a sample of American and Brazilian college students. We applied about 187 questionnaires among economics students at Purdue University and also at Universidade Federal de Pernambuco (UFPE). We found that American college students have a higher probability of self-reporting as happier than Brazilian students. We also found interesting differences: (i) women are happier than men at Purdue, but men are happier than women at UFPE; (ii) family background does not seem to have a clear impact on happiness among Purdue students, but it certainly has a direct impact on happiness among UFPE students; (iii) "extra money" is an important factor for happiness in the two groups, but it is definitely more important for male students at UFPE; (iv) leisure is the key factor for happiness among Purdue students; and (v) policy towards improvements in public safety would have a stronger effect on happiness among economics UFPE students than among those who attend the Purdue University.

Keywords: Subjective Well-Being, Relative Income Differences, Brazil, United States.

JEL Codes: O57, Z13.

\footnotetext{
${ }^{*}$ Submitted in June 2007. Revised in June 2009. We are indebted to Werner Baer for helpful conversation and also to Hadi Esfahani, Donald Pianto, two anonymous referees, and the Editor for insightful comments. We are responsible for any error. Cavalcanti and Nogueira are also thankful to Conselho Nacional de Desenvolvimento Científico e Tecnológico (CNPq) for financial support. Part of this paper was written while Tiago Cavalcanti was visiting the Department of Economics at Purdue University. He is thankful to the people at Purdue University, especially Gabriele Camera, for their hospitality.

${ }^{* *}$ Faculty of Economics, University of Cambridge, UK. Corresponding author. E-mail: tvdvc2@cam.ac.uk

${ }^{* * *}$ Faculty of Economics, University of Cambridge, UK.

**** Department of Economics Universidade Federal de Pernambuco, Brazil.
} 


\section{Introduction}

According to large surveys conducted by tourist and travel agencies abroad, Brazil is stereotypically portrayed as a country that is prodigal with joyfulness and "eternal celebration". Such surveys indicate that happiness is one of the main characteristics of Brazilian people. ${ }^{1}$ The Brazilian Tourist Board (EMBRATUR) refers to Bahia, a northeastern Brazilian state, as the land of happiness. After a visit to Brazil, filmmaker Fellini once said that he was convinced that Brazilians were the happiest people in the world. Brazilian anthropologist Ribeiro (1996) declared that Brazilians exhibit unique joyfulness in life that is hard to find in other parts of the world. ${ }^{2}$

This article analyzes happiness in Brazil in a comparative perspective. It studies whether there are any differences in the overall reported satisfaction with life among Brazilian and American college students. We use two samples collected from direct surveys of college students at Purdue University in Indiana, United States, and at Universidade Federal de Pernambuco (UFPE), Brazil. ${ }^{3}$ We asked about the students' overall satisfaction with life (the questionnaires are shown in Appendix A). We also asked what would make them happier. Students had eight possible choices, which they had to rank from one to eight (see question 2 in the two questionnaires). We think that it is important to compare two similar groups in two different societies. On the one hand, they share similar wishes and preoccupations, such as their academic grades, future career, and love life issues, as any college student around the world. On the other hand, socioeconomic conditions and social norms are far different in these two societies. ${ }^{4}$

\footnotetext{
${ }^{1}$ See the official EMBRATUR website (www.braziltour.com).

2 "This is Brazil, a better Rome, of mixed race, bathed in black blood, in indigenous blood, marked by suffering, and of tropical climate. With the overwhelming advantages of a huge winterless world where the green and the beautiful are found in great plenty and where life is prettiest. And whose dwellers are filled with a joy of living that is not seen anywhere else." (Darcy Ribeiro's statement aired on TV Cultura, 1995. Available at: http://www.tvcultura. com.br/aloescola/estudosbrasileiros/povobrasileiro/index.htm).

${ }^{3}$ UFPE is the leading University in research in the Brazilian Northeast. It has about 35,000 students. Purdue University in West Lafayette has about 38,000 students. Both are public universities, but while there are no tuition fees at UFPE, the estimated annual expenses at Purdue University are about US\$17,000.

${ }^{4}$ Corbi and Menezes-Filho (2006) also study the empirical determinants of happiness in Brazil using microdata from the World Values Survey. We see our work as complementary to theirs, because:

(i) we focus on a particular group of the society (college students) while they use a representative sample of the country; and

(ii) in our survey we can study how different factors (e.g., extra money, public safety, more leisure, among others) can contribute to students' happiness in the two societies. We believe that this is an important extension.
} 
Our results show that there is a higher fraction (about two times higher) of students at Purdue than at UFPE who self-report to be very happy. This result is robust to the introduction of individual control variables, such as age, gender, family income, and working status. Therefore, at least in our sample, college students at Purdue have a higher probability to self-report as being very happy than those at UFPE. There are, however, some important differences. Women are reportedly happier (this is a statistically significant effect) than men at Purdue, but men are happier than women at UFPE (no statistical significance). We also show that family wealth is an important determinant of happiness in Brazil, but not in the United States.

Regarding the factors that make students happier, we found that extra money buys some extra happiness among male UFPE students (extra money does not affect happiness in women and men differently at Purdue). Interestingly, additional leisure is the key contributing factor for happiness among Purdue students, but it is not the key factor at UFPE; and UFPE students have a higher probability of ranking "less violence" as an important condition for their happiness than do Purdue students.

Psychologists find significant validations in such well-being surveys. As reported by Layard (2003), most people find it easy to say how good they are feeling and although people's feelings fluctuate day to day, there is a huge difference in the general level of happiness between different people. "The idiosyncratic effects of recent, irrelevant events are likely to average out in representative population samples" (Kahneman and Krueger, 2006, p. 7). ${ }^{5}$ Moreover, individuals who report higher levels of happiness smile more and meet other psychological measures of wellbeing (see Davidson et al. (2000)).

In addition to this Introduction, this paper is organized into four more sections. The next section describes the data and summarizes some statistics concerning the two samples. Section 3 investigates whether or not there are any differences in self-reported happiness. Section 4 investigates what factors make college students happier at the two universities. The last section concludes this paper.

\section{Data}

This paper uses data from two samples collected by the authors using direct surveys of college students at Purdue University in Indiana, United States, and at Universidade Federal de Pernambuco (UFPE), Brazil. We applied 91 and 96 questionnaires among students at Purdue and at UFPE, respectively (see a sample

\footnotetext{
${ }^{5}$ Since we do not make a retrospective assessment, we might be placing a great weight on some particular (peak or bottom) experience - current mood or a particular event. However, we believe that such experiences will average out over the two samples. In addition, there is no particular reason for the effects to be completely different among Purdue and UFPE students. Besides, we do not only focus on the comparison of reported happiness, but also on the factors that make each group happier.
} 
of the two questionnaires in Appendix A, and the data description in Appendix C). Students at Purdue University were taking an intermediate macroeconomics class in the fall and spring of the 2005/2006 academic year, while at UFPE they were taking an intermediate class in public finance in the same academic year. ${ }^{6}$ It is important to highlight that these two courses are mandatory for economics students at Purdue University and UFPE, respectively. Therefore, both samples represent well the population of economics students in a given particular year in each university.

Our main variable, self-reported happiness is constructed from a question with three possible answers: I am not happy, I am pretty happy, and I am very happy. ${ }^{7}$ Using this question, we compared how students at Purdue and UFPE self-reported as being happy, controlling for some individual and social economic conditions. Next, we asked students to rank (among eight choices) what would make them happier (see question 2 in the questionnaires). The remaining four questions collected some socioeconomic conditions of the individuals, such as age, gender, parents' income, and working status.

Table 1 summarizes the frequency of individuals in the two samples according to gender, parents' income, and working status. The gender division in the two samples was almost the same, with about $30 \%$ of women in each sample. Regarding parents' income, we observed that the proportion of students coming from a low-income family is roughly the same in the two samples; however, there is a higher frequency of students at Purdue than at UFPE who report to have come from a high-income family. ${ }^{8}$ Table 1 also shows that the frequency of students working full-time is higher at UFPE than at Purdue. Nevertheless, there is a higher frequency of part-time working students at Purdue than at UFPE.

\footnotetext{
${ }^{6}$ We conjecture that the courses taken by students do not affect their self-reported happiness. The questionnaires were applied in the fall of 2005 and spring of 2006 at Purdue University. Ordered regression analysis shows that there is no statistical difference in well-being among students in the fall and in the spring. At UFPE, the questionnaires were applied in February 2006. As pointed out by two anonymous referees, the two samples could have been applied in the same moment in time. This would have some effect on the comparison of happiness between Purdue and UFPE students and would produce some bias in the results of Section 3 . However, this probably would not have any effect on how some factors (such as public safety) affect subjective happiness in the two samples.

${ }^{7}$ Notice that this is similar to the question from the General Social Survey (GSS) in the United States, used by many authors, such as Alesina et al. (2004), and Blanchflower and Oswald (2004).

${ }^{8}$ It is important to highlight that families are classified into low, middle, or high-income based on income in each country separately. In the questionnaire, we do not ask what their parents' annual income was, but whether they came from a low, middle, or high-income family.
} 
Table 1

Proportion of individuals by gender, income, and working status

\begin{tabular}{lcc}
\hline & Purdue students & UFPE students \\
\hline Male & 0.71 & 0.68 \\
Female & 0.29 & 0.32 \\
Low income & 0.05 & 0.07 \\
Middle income & 0.62 & 0.81 \\
High income & 0.33 & 0.12 \\
Not working & 0.42 & 0.5 \\
Working part-time & 0.52 & 0.38 \\
Working full-time & 0.06 & 0.12 \\
\hline Source: Authors' survey. & &
\end{tabular}

\section{Differences in Self-Reported Happiness}

We investigated whether there was any difference in subjective reported happiness among economics students at Purdue University and at UFPE. Table 2 reports the mean and standard deviation for subjective happiness reported by students at both universities ( 1 stands for not happy, 2 for pretty happy, and 3 for very happy). Notice that the arithmetic mean in Table 2 assumes cardinality, while reported subjective happiness is an ordered number. Later on, we will report the ordered estimations using standard regression procedures. With this caveat in mind, we observe that the mean reported happiness is lower among UFPE students than among Purdue students. We also use the Mann-Whitney two-sample statistic to test the hypothesis that the two independent samples are from populations with similar distribution. The $p$ value of this test rejects this hypothesis with a $99 \%$ confidence level.

Table 2

Descriptive statistics - self-reported happiness

\begin{tabular}{lcc}
\hline & Purdue students & UFPE students \\
\hline Mean & 2.36 & 2.15 \\
Std. Dev. & 0.58 & 0.48 \\
Number of obs. & 91 & 94 \\
\hline Mann-Whitney rank test $(p$ value $)$ & 0.005 \\
\hline \multicolumn{2}{l}{ Source: Authors' survey. }
\end{tabular}

Figure 1 shows the histograms of self-reported happiness for the two samples. Notice that the two empirical distributions do not look alike, corroborating the result of the Mann-Whitney test, which rejects the null hypothesis of equality of distributions. The difference is concentrated in the upper tail of the distribution. Observe that the fraction of not happy individuals is roughly the same among Purdue (4.4\%) and UFPE students (5.3\%). However, the fraction of very happy students is about two times higher among Purdue students (40\%) than at UFPE (20\%). Consequently, the fraction of pretty happy students is higher at UFPE $(74 \%)$ than at Purdue (55\%). 
Next, we estimate the probability of students self-reporting as happy by allowing for a set of individual controls. We take advantage of individual variations and we run an ordered logit regression of the form:

$$
\text { happy }_{i}=\alpha+\beta X_{i}+\gamma \text { Purdue }_{i}+\varepsilon_{i}
$$

The dependent variable $h a p p y_{i}$ is the self-reported happiness, which can take three values (as discussed before, 1 corresponds to the lowest reported happiness level). The description of the independent variables in (1) is: $X_{i}$ a column vector ${ }^{9}$ with individual characteristics such as age, age squared, gender (male=1), indicator variables for students from low-income family, middle-income family, dummy variable if the student is not working, and another dummy variable if the student is a part-time worker. The variable $\operatorname{Purdue}_{i}$ is an indicator variable that takes value 1 if student $i$ is at Purdue and 0 if he/she is at UFPE. Table 3 summarizes the results.

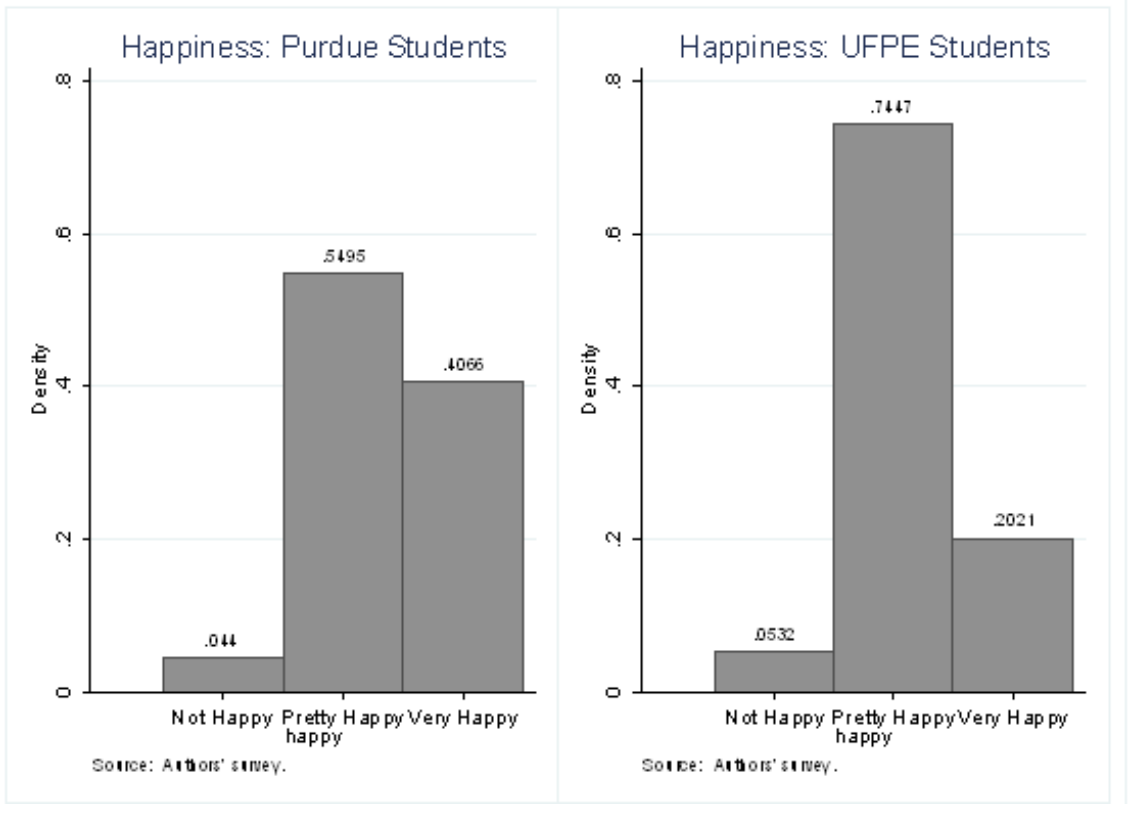

Figure 1

Distribution of self-reported happiness $X_{i}$ 


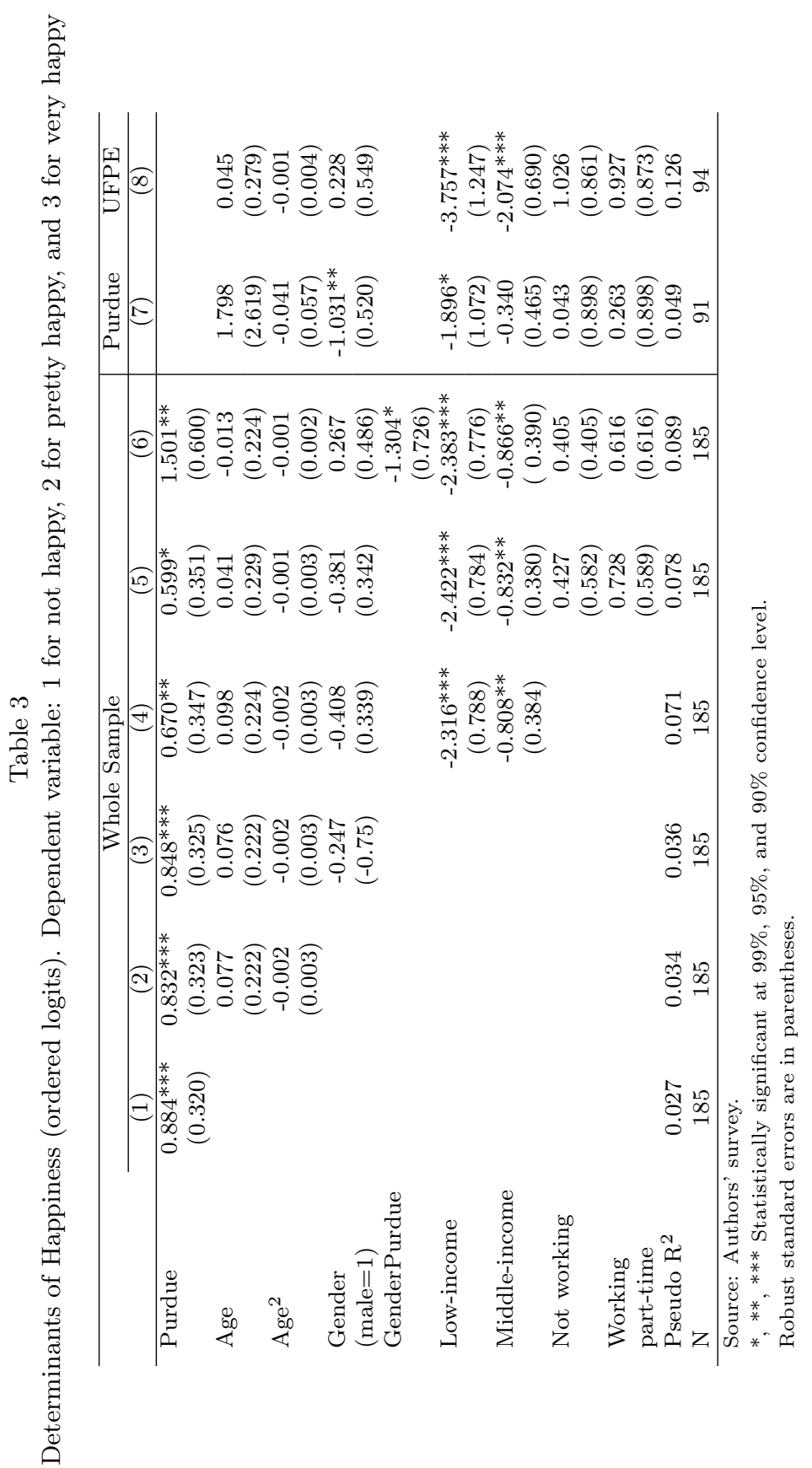


From Table 3, we observe that the coefficient of the dummy variable Purdue is positive and significant in all regressions. This is true when we use Purdue as the only independent variable (Table 3, column (1)), but also when we add other controls in the regression (Table 3 columns (2)-(6)). Therefore, we can conclude that students at Purdue University have a higher probability of selfreporting as happier than students at UFPE after controlling for a set of individual characteristics.

When we run the regression with the whole sample the coefficient of gender is negative in all regressions (Table 3 columns (3)-(5)), ${ }^{10}$ but it is not statistically different from zero. However, when we run a regression for each sample separately results are different. Women are happier than men at Purdue and this result is statistically different from zero at a $95 \%$ level of confidence (Table 3 columns (7)). This is consistent with other studies, which show that women are in fact happier than men in the United States (e.g., Blanchflower and Oswald (2004)). Among UFPE students, we observe that the sign is positive, but the coefficient is not statistically different from zero. ${ }^{11}$ When we multiply the dummy for gender by the dummy for Purdue, the sign of the coefficient of this variable is negative and statistically different from zero (Table 3, column (6)). Therefore, regarding gender differences in happiness there is no gender division in overall reported life satisfaction among UFPE students, but women report to be happier than men in the Purdue sample. This might be related to differences in the gender role in the two societies. ${ }^{12}$

Our estimates using the whole sample also show that compared to students from high-income families, those who come from low and middle-income families have a lower probability of self-reporting as happier (Table 3, columns (4) to (6)). These two dummy variables have a negative coefficient and are statistically different from zero at $99 \%$ confidence level for those students from a low-income family and at $95 \%$ confidence level for those that come from a middle-income family. Notice that the income dummy variables are constructed by asking students whether they come from low, middle, or high-income family within their own societies. This implicitly takes into account the issue about relative income. We are not comparing the level of family income in the United States with the family income level in Brazil, but the students' perception about the level of income of their families compared to the level of income of the society they belong to, which is in

\footnotetext{
${ }^{10}$ Since this variable takes value one for men and zero for women, this means that women have a higher probability of self-reporting as happier than men.

${ }^{11}$ A recent study by Graham and Felton (2006) shows that, in Latin America, men are happier than women.

${ }^{12}$ Data from the World Development Indicators show that in the United States the female unemployment rate is similar to the total unemployment rate. In Brazil, the female unemployment rate is about $50 \%$ larger than the total unemployment rate. In 2000 about $26 \%$ of the total ministerial level positions in the United States was occupied by women. Such number is only $4 \%$ in Brazil.
} 
accordance with Easterlin $(1974,1995)$. Another important issue is that family income might be correlated to other omitted variables that affect happiness, such as family background and health status. ${ }^{13}$ Therefore, the positive effect of parents' income on happiness might be spurious.

Observe, however, that the effects of income on happiness are not robust when we consider the two samples separately. ${ }^{14}$ Among Purdue students (Table 3, column (7)), parents' level of income does not have a strong effect on self-reported happiness. Only the low-income variable is statistically different from zero at the $90 \%$ confidence level. There is no statistical difference in self-reported happiness among Purdue students who come from middle and high-income families. Among students at UFPE (Table 3, column (8)), we observe that the parent's income dummies have a negative sign and are statistically different from zero at the $99 \%$ level of confidence. Therefore, UFPE students who come from high-income families have a higher probability of self-reporting as happier than those that come from low and middle-income families.

An interesting hypothetical exercise is to study the possible consequences of moving a randomly chosen student from UFPE to Purdue and vice versa. For instance, assume that a male student at UFPE belongs to the middle-income group. Such student is likely to become a low-income student at Purdue, which reduces his happiness, but he will get the benefit of the fixed effect of being at Purdue net of the effect of being male at Purdue. Using equation (6), we can observe that the overall well-being of this student will decrease or increase whether he uses the reference income group as the one in the United States (low income) or as the one in Brazil (middle income), respectively. Now, consider a female middleincome class student from UFPE and move her to Purdue. Again, such student is likely to become a low-income student at Purdue, which reduces her happiness, but she will get the benefit of the fixed effect of being a female at Purdue. Her self-reported happiness will remain the same if she uses her United States reference income group, but it will certainly increase if her reference income group is the one in Brazil. ${ }^{15}$

\footnotetext{
${ }^{13}$ Deaton (2008) shows that there is a close relationship between health status and happiness. Clearly, the omission of a health indicator might be biasing our results. However, our samples consist of college students only. Although students at UFPE do not pay any fee (while they do that at Purdue), most of the economics students at UFPE are from middle and high-income families. We therefore conjecture that health status is not an important issue for our sample and it is probably not driving any of our results.

${ }^{14} \mathrm{An}$ important caveat is needed here. According to a survey by Time magazine about $19 \%$ of Americans say they are in the richest 1\%. We believe, from informal conversations and simple analysis from the PNAD (Brazilian household survey), that most people in Brazil who report to be in the middle class are indeed at the top $1 \%$ of income.

${ }^{15}$ Of course, this is a static exercise. The move from UFPE to Purdue might have a strong impact on career opportunities for a student at UFPE and the overall long-run impact on wellbeing might be very different.
} 


\section{What would Make Students Happier?}

In this section we study some factors that would make students happier. This is based on the answers to question 2 in our questionnaire (see Appendix A and the description of the data in Appendix C). In this question, we ask students what would make them happier. They had eight possible choices, which they ranked from 1 to 8 ( 1 being the most important for happiness). The factors we chose were: more money, more friends, being closer to parents and/or friends, a love story, a job, more leisure, less violence, and others.

Table 4 reports some descriptive statistics on the importance of each factor for students' happiness. Recall that 1 implies that this factor is very important for students' happiness while 8 means the opposite. Therefore, a lower mean and median suggest that the factor is relatively more important in one group than in the other. We observe that the mean and median for the two samples are quite similar (as well as the standard deviation) for almost all factors except two of them: "more leisure" and "less violence". In fact, these two factors were the only items in which the Mann Whitney rank test rejects the null hypothesis that the two samples come from the same distribution.

Observe that "more leisure" is the item with the lowest mean and median among Purdue students. In fact, about $60 \%$ of students at Purdue ranked "more leisure" as at least the second most important factor (among the eight ones listed) to increase their happiness. Only $30 \%$ of students at UFPE ranked more leisure as at least the second most important factor for happiness. The factor with lowest mean and median among UFPE students is "more money". ${ }^{16}$ The ordered regression analysis corroborates this finding and suggests that students at Purdue have a higher probability of indicating "more leisure" as an important factor for their happiness than UFPE students (see Appendix B, Table A1, and column (6)).

Regarding "less violence", the mean and median are higher at Purdue than at UFPE (see Table $4(\mathrm{~g})$ ), indicating that "less violence" would have a stronger impact on happiness at UFPE than at Purdue. This is confirmed in the ordered logit regression (see Table A1, column (7)). ${ }^{17}$ With respect to the other factors, we have the following:

\footnotetext{
${ }^{16}$ Notice, however, that the mean and median for "more money" are lower for Purdue students than for UFPE ones.

${ }^{17}$ When we use the dependent variable that takes value 1 if students ranked "less violence" as at least the second factor in importance for happiness, the only variable that is statistically different from zero is the Purdue dummy variable. It has a negative coefficient, which indicates that UFPE students have a higher probability of reporting "less violence" as an important factor to increase their happiness than do Purdue students.
} 
Table 4

What would make students happier?

\begin{tabular}{|c|c|c|c|}
\hline \multicolumn{2}{|c|}{ (a) More money } & \multicolumn{2}{|l|}{ (e) $\mathrm{A}$ job } \\
\hline Purdue students & UFPE students & Purdue students & UFPE students \\
\hline 3.21 & 3.26 & 3.87 & 4.31 \\
\hline Median & 3 & 4 & 5 \\
\hline Std. Dev. & 1.82 & 1.96 & 2.03 \\
\hline Number of obs. & 87 & 77 & 81 \\
\hline Mann-Whitney rank test ( $p$-value) & 0.81 & & 0.182 \\
\hline \multicolumn{2}{|c|}{ (b) More friends } & \multicolumn{2}{|c|}{ (f) More leisure } \\
\hline Mean & 3.74 & 2.66 & 3.86 \\
\hline Median & 4 & 2 & 4 \\
\hline Std. Dev. & 1.98 & 1.62 & 2.01 \\
\hline Number of obs. $\quad 74$ & 81 & 80 & 87 \\
\hline Mann-Whitney rank test ( $p$-value) & 0.32 & & 0.001 \\
\hline \multicolumn{2}{|c|}{ (c) Living closer to parents/friends } & \multicolumn{2}{|c|}{ (g) Less violence } \\
\hline 3.76 & 3.86 & 6.16 & 5.06 \\
\hline Median & 4 & 7 & 6 \\
\hline Std. Dev. & 2.15 & 1.59 & 2.06 \\
\hline Number of obs. $\quad 81$ & 82 & 69 & 85 \\
\hline Mann-Whitney rank test ( $p$-value) & 0.81 & 0.001 & \\
\hline & (d) A love story & \multicolumn{2}{|c|}{ (h) Others } \\
\hline Mean & 4.02 & 6.53 & 6.39 \\
\hline Median & 4 & 8 & 8 \\
\hline Std. Dev. & 2.12 & 2.33 & 2.58 \\
\hline Number of obs. $\quad 77$ & 79 & 54 & 69 \\
\hline Mann-Whitney rank test ( $p$-value) & 0.86 & 0.97 & \\
\hline
\end{tabular}

Source: Authors' survey.

(1) "Extra money" does not impact students' happiness differently at the two universities once we control for some individual characteristics. On average, money is more important for men than for women. However, this difference in gender is only statistically significant for UFPE students. Men at UFPE have a higher probability of reporting "Extra Money" as an important factor for their happiness than do women (see Appendix B, Table A1, A2 and A3, column (1)).

(2) The factor "more friends" has a weaker contribution to happiness than does the item "more money." Moreover, the ordered logit regression shows that there is no important difference in how students rank "more friends11 at Purdue and UFPE (see column (2) in Table A1 in Appendix B).

(3) In the item "living closer to parents and friends", we observe that once we control for students' characteristics, the ordered logit analysis does not suggest that students at Purdue have a higher probability of indicating that this factor is important for their happiness than students at UFPE (see column (3) in Table A1). Interestingly, however, women have a higher probability of reporting that living closer to their parents and friends is an important factor 
for their happiness than do men, and this is only statistically significant among Purdue students.

(4) Table 4 (d) shows that "a love story" has the highest mean in both samples compared to the three previous items. Therefore, looking only at these two central measures, "a love story" is the least important factor for happiness in both samples - compared to the previous three factors. The mean and median are similar in both samples. Indeed, there is no different pattern with regard to how Purdue and UFPE students ranked this item in importance for their happiness.

(5) The mean and median of the item "a job" is roughly the same at Purdue and at UFPE (see Table 4 (e)). In fact, once we control for individual characteristics, the ordered logit regression does not suggest that students at the two universities rank a job differently in importance for happiness (see Table A1, column (5)).

\section{Concluding Remarks}

In this paper we investigate differences in overall life satisfaction among Brazilian and American economics students using a sample from Purdue and UFPE students. We find that economics Purdue students have a higher probability of self-reporting as very happy and happy than do UFPE students. This effect is statistically significant and it is also robust to a set of control variables characterizing individual and socioeconomic conditions.

We also found some interesting differences between the two groups of students. Women are happier than men at Purdue, but men are happier than women at UFPE. Family wealth does not seem to have a clear impact on happiness among Purdue students, but it certainly impacts happiness positively among UFPE students. We also found the following: "additional leisure" is the key factor for happiness among Purdue students. About $60 \%$ of students at Purdue ranked "more leisure" as at least the second most important factor (among the eight ones listed) to increase their happiness. For UFPE male students, "extra money" would definitely buy some happiness. About $38 \%$ of students at UFPE ranked "more money" as at least the second most important factor for happiness. This is, particularly, important for male college students. Finally, policy towards improvements in public safety would have a stronger effect on happiness among UFPE students than among those at Purdue. 


\section{References}

Alesina, A., Di Tella, R., \& MacCulloch, R. (2004). Inequality and happiness: Are Europeans and Americans different? Journal of Public Economics, 88:20092042.

Blanchflower, D. G. \& Oswald, A. J. (2004). Well-being over time in Britain and the USA. Journal of Public Economics, 88:1359-1386.

Corbi, R. B. \& Menezes-Filho, N. A. (2006). Os determinantes empíricos da felicidade no Brasil. Revista de Economia Política, 26:518-536.

Davidson, R. J., Jackson, D. C., \& Kalin, N. H. (2000). Emotion, plasticity, context and regulation: Perspective from affective neuroscience. Psychological Bulletin, 126:890-906.

Deaton, A. (2008). Income, aging, health and wellbeing around the world: Evidence from the Gallup World Poll. Journal of Economic Perspectives, 22:53-72.

Easterlin, R. A. (1974). Does economic growth improve the human lot? Some empirical evidence. In David, P. A. \& Reader, M. W., editors, Nations and Households in Economic Growth: Essays in Honor to Moses Abramowitz. Academic Press, New York.

Easterlin, R. A. (1995). Will raising the incomes of all increase the happiness of all? Journal of Economic Behavior and Organization, 27:35-47.

Graham, C. \& Felton, A. (2006). Inequality and happiness: Insights from Latin America. Journal of Income Inequality, 4:107-122.

Kahneman, D. \& Krueger, A. (2006). Developments in the measurement of subjective well-being. Journal of Economic Perspective, 20:3-24.

Layard, R. (2003). Happiness: Has social science a clue? Lionel Robbins Memorial Lectures, London School of Economics.

Ribeiro, D. (1996). O Povo Brasileiro: A Formação e o Sentido do Brasil. Companhia das Letras, 2nd. edition. 
Appendix A: Questionnaires

\section{Questionnaire: Subject Happiness}

Are you Happy?

1 - I am not happy 2 - I am pretty happy 3 - I am very happy

What would make you happier? (Please, rank you answer. Use 1, 2, 3, 4, 5, 6 ,

7 , and 8 to describe which factor makes you happier; 1 being the most important.)

- More money

- Living closer to parents and/or friends

- A Job

— Less violence

- More friends

- A love story

- More leisure

- Others

Age: -

Gender Male

Female $\square$

Do you come from a?

1 - Low-income family $\quad 2$ - Middle-income family 3 - High-income family

Do you work?

1 - No, I do not work 2 - Yes, I work part-time 3 - Yes, I work full-time 


\section{Appendix B: Additional Tables}

Table A1 - (Whole Sample) Dependent variable: 7 dependent variables. How students ranked the following factors for their happiness: More money, more friends, living closer to parents/friends, a love story, a job, more leisure, and less violence

\begin{tabular}{|c|c|c|c|c|c|c|c|}
\hline & Money & Friends & Parents & Love & Job & Leisure & Violence \\
\hline & $(1)$ & $(2)$ & $(3)$ & $(4)$ & $(5)$ & $(6)$ & $(7)$ \\
\hline \multirow[t]{2}{*}{ Purdue } & -0.014 & 0.333 & -0.121 & -0.125 & -0.385 & $-1.179 * * *$ & $1.181^{* * *}$ \\
\hline & $(0.297)$ & $(0.322)$ & $(0.305)$ & $(0.316)$ & $(0.307)$ & $(0.307)$ & $(0.325)$ \\
\hline \multirow[t]{2}{*}{ Age } & -0.178 & 0.213 & 0.043 & -0.149 & -0.128 & 0.049 & $-0.541^{* *}$ \\
\hline & $(0.196)$ & $(0.206)$ & $(0.199)$ & $(0.208)$ & $(0.224)$ & $(0.195)$ & $(0.216)$ \\
\hline \multirow[t]{2}{*}{$\mathrm{Age}^{2}$} & 0.002 & -0.002 & -0.001 & 0.002 & -0.001 & -0.001 & $0.008 * *$ \\
\hline & $(0.003)$ & $(0.003)$ & $(0.003)$ & $(0.003)$ & $(0.003)$ & $(0.003)$ & $(0.003)$ \\
\hline \multirow{2}{*}{$\begin{array}{l}\text { Gender } \\
(\text { male }=1)\end{array}$} & $-0.759 * *$ & 0.034 & $0.642^{* *}$ & 0.291 & -0.066 & 0.187 & 0.806 \\
\hline & $(0.305)$ & $(0.315)$ & $(0.307)$ & $(0.325)$ & $(0.313)$ & $(0.311)$ & $(0.326)$ \\
\hline \multirow[t]{2}{*}{ Low-income } & -0.707 & 0.902 & 0.707 & -0.461 & -0.271 & 0.438 & 0.724 \\
\hline & $(0.604)$ & $(0.669)$ & $(0.628)$ & $(0.683)$ & $(0.636)$ & $(0.603)$ & $(0.607)$ \\
\hline \multirow{2}{*}{$\begin{array}{l}\text { Middle- } \\
\text { income }\end{array}$} & 0.198 & -0.161 & -0.409 & -0.494 & -0.117 & $0.724^{* *}$ & $0.879^{* *}$ \\
\hline & $(0.358)$ & $(0.375)$ & $(0.366)$ & $(0.376)$ & $(0.384)$ & $(0.339)$ & $(0.358)$ \\
\hline \multirow[t]{2}{*}{ Not working } & -0.218 & 0.138 & 0.757 & 0.318 & -0.857 & 0.489 & -0.367 \\
\hline & $(0.456)$ & $(0.541)$ & $(0.506)$ & $(0.65)$ & $(0.551)$ & $(0.509)$ & $(0.551)$ \\
\hline \multirow{2}{*}{$\begin{array}{l}\text { Working } \\
\text { part-time }\end{array}$} & -0.298 & 0.419 & 0.466 & 0.477 & -0.743 & 0.473 & 0.045 \\
\hline & $(0.466)$ & $(0.548)$ & $(0.497)$ & $(0.480)$ & $(0.546)$ & $(0.513)$ & $(0.539)$ \\
\hline \multirow[t]{2}{*}{ Not happy } & -0.958 & -0.389 & 0.107 & 0.204 & -0.111 & $-1.115^{*}$ & -0.382 \\
\hline & $(0.735)$ & $(0.751)$ & $(0.636)$ & $(0.666)$ & $(0.746)$ & $(0.636)$ & $(0.704)$ \\
\hline \multirow[t]{2}{*}{ Happy } & -0.315 & 0.467 & 0.196 & 0.043 & 0.167 & $-0.632^{* *}$ & -0.341 \\
\hline & $(0.316)$ & $(0.328)$ & $(0.314)$ & $(0.330)$ & $(0.326)$ & $(0.316)$ & $(0.350)$ \\
\hline Pseudo $\mathrm{R}^{2}$ & 0.021 & 0.017 & 0.022 & 0.006 & 0.019 & 0.041 & 0.045 \\
\hline $\mathrm{N}$ & 169 & 153 & 161 & 154 & 157 & 165 & 152 \\
\hline
\end{tabular}

Source: Authors' survey.

$*, * *, * * *$ Statistically significant at $90 \%, 95 \%$, and $99 \%$ confidence level.

Robust standard errors are in parentheses. 
Table A2 - (Purdue Sample) Dependent variable: 7 dependent variables. How students ranked the following factors for their happiness: More money, more friends, living closer to parents/friends, a love story, a job, more leisure, and less violence

\begin{tabular}{|c|c|c|c|c|c|c|c|}
\hline & Money & Friends & Parents & Love & Job & Leisure & Violence \\
\hline & (1) & $(2)$ & $(3)$ & $(4)$ & $(5)$ & $(6)$ & $(7)$ \\
\hline \multirow[t]{2}{*}{ Age } & 1.171 & 3.049 & -1.465 & 0.016 & -2.183 & 3.235 & -2.881 \\
\hline & $(2.384)$ & $(2.722)$ & $(2.337)$ & $(3.086)$ & $(2.723)$ & $(2.502)$ & $(2.880)$ \\
\hline \multirow[t]{2}{*}{$\mathrm{Age}^{2}$} & -0.025 & -0.065 & 0.025 & 0.002 & 0.047 & -0.065 & 0.052 \\
\hline & $(0.051)$ & $(0.060)$ & $(0.051)$ & $(0.068)$ & $(0.059)$ & $(0.054)$ & $(0.063)$ \\
\hline \multirow{2}{*}{$\begin{array}{l}\text { Gender } \\
(\text { male }=1)\end{array}$} & -0.444 & -0.83 & $0.868^{*}$ & 0.167 & -0.385 & 0.347 & $0.921^{*}$ \\
\hline & $(0.476)$ & $(0.517)$ & $(0.494)$ & $(0.538)$ & $(0.496)$ & $(0.501)$ & $(0.562)$ \\
\hline \multirow[t]{2}{*}{ Low-income } & -0.661 & -0.839 & 1.376 & -0.217 & 0.543 & 0.47 & -0.327 \\
\hline & $(0.861)$ & $(0.867)$ & $(0.895)$ & $(1.159)$ & $(0.956)$ & $(0.831)$ & $(0.878)$ \\
\hline \multirow{2}{*}{$\begin{array}{l}\text { Middle- } \\
\text { income }\end{array}$} & -0.001 & -0.527 & -0.637 & $-0.932 * *$ & 0.174 & 0.472 & $1.106^{* *}$ \\
\hline & $(0.434)$ & $(0.468)$ & $(0.467)$ & $(0.443)$ & $(0.487)$ & $(0.442)$ & $(0.545)$ \\
\hline \multirow[t]{2}{*}{ Not working } & 0.165 & 1.382 & $1.937^{* *}$ & -0.042 & -0.812 & -0.326 & -0.723 \\
\hline & $(0.794)$ & $(0.891)$ & $(0.881)$ & $(0.766)$ & (1.219) & (1.069) & $(1.429)$ \\
\hline \multirow{2}{*}{$\begin{array}{l}\text { Working } \\
\text { part-time }\end{array}$} & 0.425 & 1.322 & 1.339 & 0.527 & -0.975 & 0.201 & -0.004 \\
\hline & $(0.787)$ & $(0.890)$ & $(0.856)$ & $(0.756)$ & $(1.200)$ & $(1.052)$ & $(1.418)$ \\
\hline \multirow[t]{2}{*}{ Not happy } & 0.133 & 1.251 & -0.774 & 0.344 & 0.067 & $-1.829^{*}$ & $-1.595^{*}$ \\
\hline & (1.098) & $(0.949)$ & $(0.968)$ & $(0.967)$ & $(0.965)$ & $(1.023)$ & $(0.981)$ \\
\hline \multirow[t]{2}{*}{ Happy } & -0.208 & -0.121 & -0.076 & -0.532 & 0.606 & -0.677 & -0.195 \\
\hline & $(0.411)$ & $(0.441)$ & $(0.428)$ & $(0.439)$ & $(0.428)$ & $(0.429)$ & $(0.481)$ \\
\hline Pseudo $\mathrm{R}^{2}$ & 0.011 & 0.076 & 0.029 & 0.011 & 0.014 & 0.042 & 0.088 \\
\hline $\mathrm{N}$ & 84 & 81 & 77 & 84 & 77 & 80 & 69 \\
\hline
\end{tabular}

Source: Authors' survey.

$*, * *, * * *$ Statistically significant at $90 \%, 95 \%$, and $99 \%$ confidence level.

Robust standard errors are in parentheses. 
Table A3 - (UFPE Sample) Dependent variable: 7 dependent variables. How students ranked the following factors for their happiness: More money, more friends, living closer to parents/friends, a love story, a job, more leisure, and less violence

\begin{tabular}{|c|c|c|c|c|c|c|c|}
\hline & Money & Friends & Parents & Love & Job & Leisure & Violence \\
\hline & (1) & $(2)$ & $(3)$ & $(4)$ & $(5)$ & (6) & $(7)$ \\
\hline \multirow[t]{2}{*}{ Age } & -0.21 & 0.123 & 0.274 & -0.07 & -0.22 & -0.057 & -0.393 \\
\hline & $(0.226)$ & $(0.230)$ & $(0.229)$ & $(0.241)$ & $(0.251)$ & $(0.222)$ & $(0.247)$ \\
\hline \multirow[t]{2}{*}{$\mathrm{Age}^{2}$} & 0.002 & -0.001 & -0.004 & 0.001 & 0.001 & 0.001 & 0.006 \\
\hline & $(0.003)$ & $(0.003)$ & $(0.003)$ & $(0.003)$ & $(0.004)$ & $(0.003)$ & $(0.003)$ \\
\hline \multirow{2}{*}{$\begin{array}{l}\text { Gender } \\
(\text { male }=1)\end{array}$} & $-1.008^{* *}$ & 0.554 & 0.341 & $0.737^{*}$ & 0.287 & 0.373 & -0.458 \\
\hline & $(0.433)$ & $(0.444)$ & $(0.433)$ & $(0.453)$ & $(0.435)$ & $(0.414)$ & $(0.434)$ \\
\hline \multirow[t]{2}{*}{ Low-income } & -0.468 & $2.912^{* * *}$ & 0.154 & 0.023 & -0.937 & 0.647 & 1.332 \\
\hline & $(0.984)$ & $(1.077)$ & $(1.028)$ & $(1.076)$ & $(0.968)$ & $(0.946)$ & $(0.904)$ \\
\hline \multirow{2}{*}{$\begin{array}{l}\text { Middle- } \\
\text { income }\end{array}$} & 0.601 & 0.474 & -0.143 & 0.337 & -0.651 & 0.878 & 0.998 \\
\hline & $(0.685)$ & $(0.730)$ & $(0.772)$ & $(0.832)$ & $(0.696)$ & $(0.595)$ & $(0.639)$ \\
\hline \multirow[t]{2}{*}{ Not working } & -0.637 & -0.905 & 0.426 & 0.427 & $-1.060^{*}$ & 0.742 & -0.342 \\
\hline & $(0.593)$ & $(0.683)$ & $(0.651)$ & $(0.663)$ & $(0.628)$ & $(0.599)$ & $(0.645)$ \\
\hline \multirow{2}{*}{$\begin{array}{l}\text { Working } \\
\text { part-time }\end{array}$} & -0.855 & 0.001 & 0.515 & 0.352 & -0.828 & 0.301 & 0.038 \\
\hline & $(0.602)$ & $(0.689)$ & $(0.655)$ & $(0.641)$ & $(0.622)$ & $(0.593)$ & $(0.617)$ \\
\hline \multirow[t]{2}{*}{ Not happy } & $-1.977^{*}$ & $-2.055^{*}$ & 0.304 & 0.476 & -0.433 & -0.369 & -0.098 \\
\hline & $(1.083)$ & $(1.227)$ & $(0.927)$ & $(1.078)$ & $(1.285)$ & $(0.895)$ & $(1.055)$ \\
\hline \multirow[t]{2}{*}{ Happy } & -0.644 & 1.344 & 0.664 & 0.793 & -0.401 & -0.599 & -0.469 \\
\hline & $(0.520)$ & $(0.565)$ & $(0.521)$ & $(0.565)$ & $(0.523)$ & $(0.512)$ & $(0.549)$ \\
\hline Pseudo $\mathrm{R}^{2}$ & 0.046 & 0.08 & 0.015 & 0.019 & 0.043 & 0.02 & 0.02 \\
\hline $\mathrm{N}$ & 85 & 79 & 80 & 77 & 80 & 85 & 83 \\
\hline
\end{tabular}

Source: Authors' survey.

$*$, **,*** Statistically significant at $90 \%, 95 \%$, and $99 \%$ confidence level.

Robust standard errors are in parentheses. 


\section{Appendix C: Data Appendix}

This Appendix describes the data. Below are the variables. The raw data collected by the authors can be found at www.econ.cam.ac.uk/ faculty/cavalcanti.

Happy - Answer to question 1 in the questionnaire: Value 1 for not happy, 2 for pretty happy, and 3 for very happy.

Money - Answer to question 2 in the questionnaire. It is an ordered number from 1 to 8 . Value 1 means that this factor is the most important one for happiness.

Friends - Answer to question 2 in the questionnaire. It is an ordered number from 1 to 8 . Value 1 means that this factor is the most important one for happiness.

Prentfrnd - Answer to question 2 in the questionnaire. It is an ordered number from 1 to 8 . Value 1 means that this factor is the most important one for happiness.

Love - Answer to question 2 in the questionnaire. It is an ordered number from 1 to 8 . Value 1 means that this factor is the most important one for happiness.

$\boldsymbol{J o b}$ - Answer to question 2 in the questionnaire. It is an ordered number from 1 to 8 . Value 1 means that this factor is the most important one for happiness.

Leisure - Answer to question 2 in the questionnaire. It is an ordered number from 1 to 8 . Value 1 means that this factor is the most important one for happiness.

Violence - Answer to question 2 in the questionnaire. It is an ordered number from 1 to 8 . Value 1 means that this factor is the most important one for happiness.

Others - Answer to question 2 in the questionnaire. It is an ordered number from 1 to 8 . Value 1 means that this factor is the most important one for happiness. 
Age - Students' reported age.

Gender - Male 1, female 0.

Income -1 for students that come from low-income families, 2 for students that come from middle-income families, and 3 for students that come from highincome families.

Work - 1 not working, 2 working part-time, and 3 working full-time.

Purdue - 1 for Purdue students; and 0 for UFPE students. 